\title{
El método de análisis en grupo: un instrumento de formación en mediación (The Group Analysis Method: An I nstrument for Training in Mediation)
}

MAURicio García PeÑAfiel* YVES CARTUYVELS*

García Peñafiel, M., y Cartuyvels, Y., 2018. El método de análisis en grupo: un instrumento de formación en mediación. Received 02 February 2018. Accepted 11 May 2018. Oñati Socio-legal Series [online], 9(4), 477-493. Available from: https://doi.org/10.35295/osls.iisl/0000-0000-0000-1091

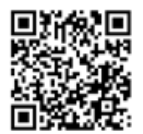

\section{Resumen}

El artículo presenta el método de análisis en grupo (MAG), en tanto método cualitativo de investigación acción, y sus relaciones con la mediación. Partiendo de una experiencia de formación a la mediación en Bruselas, los autores muestran como este método de investigación acción es relevante para formar mediadores y pertinente para la práctica misma de la mediación. Después de presentar brevemente el programa de formación, se presentan los fundamentos del MAG, sus características principales en la práctica y las distintas etapas del proceso de un análisis en grupo. Finalmente, se realizan algunas reflexiones y análisis tendientes a mostrar las correspondencias de este proceso de análisis con el trabajo y las finalidades de la mediación.

\section{Palabras clave}

Método de análisis en grupo; mediación; método alternativo de resolución de conflictos

\begin{abstract}
The paper presents the Group Analysis Method (GAM), as a qualitative field research methodology, and its relations with mediation. Starting from an experience developed in the frame of a mediation program in Brussels, the authors show how this action research methodology is relevant not only to train mediators but also for the practice of mediation itself. After a brief presentation of the learning program, the foundations of the GAM, its main characteristics and different stages of the analysis process are presented. Finally, some insights are proposed to enlighten the correspondences between GAM and mediation process and purposes.
\end{abstract}

\footnotetext{
* Mauricio García Peñafiel: Doctor en Psicología y Psicoanalista, profesor de Université Saint Louis Bruxelles (Bruselas, Bélgica), profesor invitado de Université Catholique de Louvain (Lovaina, Bélgica). Email: mauricio.garcia@usaintlouis.be

* Yves Cartuyvels: master en derecho y doctor en criminología, profesor Université Saint Louis - Bruxelles (Bruselas, Bélgica). Email: yves.cartuyvels@usaintlouis.be
}

\section{(cc) EY-No-ND}




\section{Key words}

Group analysis method; mediation; alternative method of conflict resolution 


\section{Índice / Table of contents}

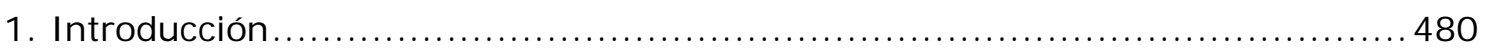

2. El certificado interuniversitario en mediación de la Académie de Louvain ........481 481

3. Breve recorrido de los fundamentos del método de análisis en grupo (MAG) .. 482

4. El método de Análisis en Grupo (MAG) como instrumento de formación .........487

5. Conclusiones: las relaciones entre el MAG y la mediación .........................490

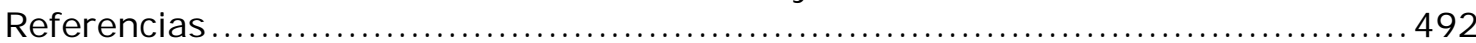




\section{I ntroducción}

Las ciencias humanas se han volcado crecientemente, en las últimas décadas, hacia la investigación de terreno, hacia la observación directa de los individuos y la inmersión en los grupos, culturas y subculturas. En todas las ciencias clínicas, sociales o antropológicas - que han ido conduciendo su investigación de esta forma - apareció un problema metodológico mayor: ¿Cómo hacer dicha investigación con rigor? ¿Cómo construir datos y cómo formalizarlos? ¿Cómo separar la descripción de los hechos de la interpretación del investigador? La lista de preguntas y de problemas metodológicos planteados por las aproximaciones de terreno o cualitativas es larga, y podrían prolongarse aún más en un campo de investigación-acción como la mediación. Uno de los asuntos en que la discusión se fue centrando es el problema del observador: por su observación y su presencia, el observador altera los hechos y los influye. Es lo que se ha dado en Ilamar "la paradoja del observador". En la medida que se fue atendiendo a los efectos de la interacción observador/observado se planteó la cuestión del control y de la fiabilidad de los hechos, y apareció el problema de las condiciones que fundan la inducción en los trabajos cualitativos.

En nuestros días, pese al constructivismo que ha hecho mella, esta discusión es ineludible. Ya no basta afirmar un primado de la teoría que nos pondría al abrigo de este tipo de consideraciones; la discusión mencionada plantea una exigencia frente a la cual es necesario reflexionar, pensar y ensayar modelos. Algunos podrían preguntarse si las ciencias humanas y sus prácticas, como la mediación, están en condiciones de liberarse del empirismo trastabillante o del teoricismo desmesurado, para entrar en la edad del rigor, construyendo un modelo fuerte que aceptaría como legítimas sólo operaciones científicamente bien fundadas. Si la cuestión es planteada en estos términos, la respuesta nos parece ser negativa, ya que ello implicaría borrar o desconsiderar todo lo que hay de inesperado, imprevisto y de heurístico en la investigación - y en el trabajo de terreno -, en los cuales siempre emergen observaciones, experiencias o discursos que nos hacen modificar nuestras hipótesis iniciales o las orientan de otro modo.

Con todo, la discusión metodológica contemporánea debería empujarnos a desarrollar una conciencia crítica respecto a la investigación o la investigación/acción que desarrollamos. Dicho de otro modo, la investigación de terreno podría armarse de un método $y$, al mismo tiempo, seguir funcionando en el interior de una perspectiva heurística y empírica. El término "empirismo" que empleamos aquí no tiene en absoluto el sentido del positivismo que cree poder restringirse a los hechos puros y duros; significa, más bien, que, en las prácticas como la psicoterapia, la mediación, la intervención psicosocial o la etnografía, por las condiciones en que estas se ejercen, los materiales y las operaciones que estas efectúan, conllevan necesariamente una dosis de impureza, es decir, de inadecuación a las exigencias de validación y de objetivación científicas ${ }^{1}$. Por supuesto que dicha impureza puede ser reducida, limitada o explicitada, pero su anulación pareciera ser imposible, a riesgo de hacer desaparecer todo el interés de la investigación de terreno. Este tipo de investigación no puede escapar a un cierto grado de contingencia, de aproximación o de incertidumbre. Perseguir un modelo de rigor demasiado fuerte y demasiado puro puede mutilar las posibilidades de descubrimiento, y obstaculizaría múltiples operaciones que se revelan fecundas.

Esto no implica hacer apología de la despreocupación metodológica o de la ignorancia. La investigación de terreno debe darse a sí misma exigencias críticas. Es lo que diferencia un empirismo naif de un empirismo razonado y atento a sus

\footnotetext{
${ }^{1}$ Por cierto que si uno discute el concepto de la ciencia, como lo hace un Maturana (1989) por ejemplo, o Ricoeur (1965 y 1983), el problema no se plantearía en estos términos, puesto que estos autores afirman una cientificidad de las ciencias humanas, de las ciencias que se ocupan de hechos de significación. Esto conduce a afirmar que, finalmente, en toda ciencia, por el hecho de que el científico observa y habla, la objetividad ha de quedar entre paréntesis. Pero quedarse en la pura discusión epistemológica a veces es un obstáculo para avanzar en la discusión metodológica.
} 
imprecisiones necesarias, que habrá que explicitar (y no ocultar detrás de tablas estadísticas).

En cierto modo, esta doble exigencia sitúa al etnógrafo, al clínico y a todo actor de terreno en una suerte de "ambivalencia epistemológica" (Schwartz 1993), ya que, exigiéndose una conciencia crítica y metodológica de sus procedimientos y resultados, aceptan tolerar una parte de "artesanía", de contingencia e incertidumbre, configurando modelos necesariamente flexibles.

Esta posición en el campo de la mediación y de las ciencias humanas implica tomar a la letra la palabra "método" (del griego meth-odos) en cuanto camino a través del cual se busca o persigue un destino. Según Lalande (1997), pese a diversas variantes, "método" implica siempre la idea "de una dirección definible y regularmente seguida en una operación del espíritu" (Lalande 1997, p. 264). Un debate doctrinal mayor, que atravesó toda la filosofía en torno a este concepto, es el problema de saber si un método puede ser determinado a priori, independientemente de su aplicación, o si debiese ser determinado a posteriori, caso en que la formulación de un método sólo sería útil cuando es descubierto en una operación efectiva del espíritu, de tal suerte que su formulación no sería más que el esquema más o menos simplificado. Este debate, aún abierto, concierne directamente lo que aquí abordaremos. El sociólogo, el psicólogo o el mediador, aun cuando se dotan de instrumentos críticos y de dispositivos previos al encuentro con su terreno, nunca llegan a formular una metodología a priori, sino que intentan tratar metódicamente lo que encuentran, asunto que no es lo mismo.

¿Cómo se lleva adelante un proceso de mediación? El que se reconozca ampliamente que no hay un método estándar ni un camino único, que la lógica del caso a caso es la más razonable para preservar la heterogeneidad de las prácticas y la amplitud de acogida que la mediación ofrece, no debería impedirnos reflexionar, por momentos, sobre métodos que nos ayuden a formalizar lo que acontece en un proceso de mediación. No se trata de reducir este método alternativo de resolución de conflictos a un método, sino de examinar qué es lo que un método con conexiones con el proceso de mediación puede iluminar, describir, o ayudar a pensar, respecto a las arenas movedizas de la mediación, sin pretender substituirse al "hibridismo de los modelos" (Faget 2010) que es característico de su práctica.

Presentaremos a continuación un método de investigación en Ciencias Sociales, el Método de Análisis en Grupo (MAG), que usamos como instrumento de formación en el marco de un certificado en mediación en Bélgica. Procederemos en cuatro tiempos:

Capítulo 2. Una muy breve presentación de este certificado en mediación;

Capítulo 3. Un recorrido breve sobre los fundamentos del método en tanto instrumento de investigación/acción en ciencias sociales;

Capítulo 4. Una presentación más detallada del MAG tal como nosotros la utilizamos en tanto instrumento de formación en un certificado en mediación;

Capítulo 5. Algunas reflexiones sobre este método y sus vínculos con la mediación en cuanto dispositivo de resolución de conflictos.

Desde nuestro punto de vista, la originalidad del MAG radica, por un lado, en el hecho de que comparte ciertos presupuestos y tiene elementos comunes con la mediación, $y$, por otro lado, en que este método puede ser utilizado como instrumento de mediación.

\section{El certificado interuniversitario en mediación de la Académie de Louvain}

En el 2006, tres universidades francófonas de Bélgica deciden crear un "certificado interuniversitario en mediación": la Universidad de Lovaina, la Universidad Saint Louis - Bruxelles y la Universidad de Namur. Esta formación, dirigida a un público adulto, partió de una constatación clásica: los modos alternativos de resolución de 
conflictos toman un lugar creciente en diversos sectores de la vida social, en respuesta a una crisis de legitimidad y de efectividad de los modos clásicos de resolución de conflictos.

Existen cuatro programas de formación: a) Un año de formación general en mediación, con una formación interdisciplinaria teórica y práctica; b) Un año de formación especializada en la mediación civil y comercial; c) Un año de formación especializada en la mediación familiar; d) Un año de formación especializada en mediación en contexto urbano, centrada en la mediación local, la mediación escolar, la mediación en salud y la mediación penal (MLESP).

Es en el marco de este último programa (MLESP) donde el MAG es utilizado como herramienta de formación. Este año de formación en mediación local, escolar, penal y en salud tiene un objeto un tanto particular. Se eligió trabajar conjuntamente sobre esos cuatro dominios de la mediación por cinco razones:

1. En los cuatro dominios se tratan pequeños conflictos de carácter relacional, en parte semejantes y en parte diferentes.

2. En los cuatro casos, los conflictos no son exclusivamente privados o individuales, sino que tienen lugar en un espacio público o semipúblico y movilizan la intervención de un actor institucional (la escuela, el hospital, las autoridades locales, la justicia...).

3. En los cuatro casos, el rol de actor institucional público es importante, aunque diferente: el peso de la escuela o de la institución jurídica, por ejemplo, no es el mismo en el proceso de mediación. Difieren también las expectativas respecto del mediador, en el hospital o en la mediación local.

4. En los cuatro casos, los tipos de conflicto suscitan o favorecen una aproximación transformativa de la mediación. Sobre las cuatro escenas se despliegan conflictos relacionales, cuyo tratamiento requiere referirse a los principios de recognición y empowerment más que a la lógica del problem solving o del bargaining. Esto explica que la formación que presentamos someramente ponga el acento en la cuestión de la postura del mediador.

5. La confrontación de estas diferentes escenas de la mediación, en sus semejanzas y en sus diferencias, es un material rico para reflexionar sobre cada dispositivo de mediación a la luz de los otros. Dicho de otro modo, la confrontación de las cuatro escenas, el esclarecimiento de sus particularidades institucionales, el esclarecimiento de las dificultades y de lo que está en juego en cada una, nos parecen de sumo interés para cuestionar tanto la postura del mediador como los ideales del mediador sobre cada una de las cuatro escenas.

El objetivo de la formación privilegia entonces una aproximación reflexiva, orientada por un modelo transformativo, más que técnico. No se trata tanto de enseñar técnicas comunicacionales o de resolución de conflictos, como de transmitir una reflexividad sobre la postura del mediador frente al conflicto. De este modo, la formación se organiza en tres ejes: a) Módulos de trabajo, con un mediador y un académico, respecto a cada escena de la mediación; b) Ejercicios prácticos cuyo eje gira en torno a la postura el mediador; y, c) Para cada escena se realiza un trabajo de análisis en grupo (utilizando el MAG) a partir de relatos de casos vividos y presentados por un mediador. Es este eje de la formación el que quisiéramos presentar con más detalle en este artículo. Luego de situar sus fundamentos y de describir el proceso que el método sigue, indicaremos sus conexiones con la mediación.

\section{Breve recorrido de los fundamentos del método de análisis en grupo (MAG)}

EI MAG se concibe a sí mismo como un método de investigación y de intervención. El núcleo de su práctica radica en el intento de hacer emerger el saber de los actores, haciéndolos interpretar un relato. Así, se confrontan las diversas interpretaciones que producen los miembros del grupo y no sus ideas u opiniones. El proceso pone en juego tanto las experiencias de los actores como su capacidad reflexiva, 
sobrepasando así la disociación habitual entre entrevistados que comunican material o datos, e investigadores que interpretan y analizan. El proceso puede tener efectos, producir transformaciones en las posiciones iniciales de un conflicto, por ejemplo, 0 reorientar la problemática inicial. Por ello, el MAG es también un método de intervención. Sin embargo, ¿cuáles son las bases de este método? En lo que sigue extraeremos lo que sus autores (Van Campenhoudt, Chaumont y Franssen 2005 y Van Campenhoudt, Franssen y Cantelli 2009) sitúan en el fundamento.

\section{a) Concepción relacional, plural y conflictiva de lo social}

El método se funda en una concepción relacional, plural y conflictual de los fenómenos sociales. Los participantes del grupo son aprehendidos, no de manera aislada ni individualizada, sino que en cuanto actores sociales, implicados en relaciones sociales que ocurren en contextos institucionales concretos. El método intenta entonces reconstruir o construir los fenómenos sociales en un contexto (el grupo que interpreta relatos de manera convergente y/o divergente) que recrea esta textura de la realidad social, donde los actores movilizan representaciones diversas, poseen recursos desiguales y tienen frecuentemente intereses divergentes. Captar dichas divergencias debería ser entonces un objetivo central de cualquier método en ciencias sociales, para poder dar cuenta de la textura hibrida, tensional y divergente de los fenómenos humanos. El lector podrá adivinar el interés de esta perspectiva para la mediación, donde, para poder ocuparse del conflicto, hay que darse los medios para describir, pensar y formular las oposiciones en juego. Al poner a trabajar a un grupo sobre sus interpretaciones divergentes de un relato, el MAG aspira no solo a poner de manifiesto dichas divergencias, sino a ponerse de acuerdo sobre los desacuerdos, esto es, que el grupo logre una formulación consensuada de sus divergencias. Esta es una de las operaciones más fecundas del método.

\section{b) Método pertinente a las transformaciones sociales}

EI MAG postula estar adaptado o ser más pertinente al contexto social actual. Para decirlo de manera general: la confusión relativa de referencias identitarias y la fragmentación de las experiencias sociales ha generado una trasformación de las referencias habituales. Se ha profundizado crecientemente la disociación entre la persona y el rol social, entre el mundo de lo vivido y el sistema, entre el agente y el actor. EI MAG, justamente, intenta articular estos ámbitos disociados: "reconstruir el sistema de acción del cual los participantes son parte integrante, así como combinar la implicación en la acción con la distanciación que conlleva el análisis" (Van Campenhoudt et al. 2005, p.14).

No es simple precisar el contexto de transformaciones sociales en el cual el MAG intentaría funcionar como un método más pertinente. En lo esencial, se trata de los grandes ejes de transformación que han hecho emerger la segunda modernidad. El modelo cultural del progreso y la razón se anuda, en la modernidad, a la sociedad industrial. En el marco territorial, político y cultural del Estado-nación, la sociedad industrial puede describirse como "un espacio de posiciones sociales, asociando y oponiendo grupos y clases definidas por sus posiciones en la división social del trabajo o, según el paradigma marxista, por sus relaciones sociales de producción" (Van Campenhoudt et al. 2005, p. 22). Por otro lado, la sociedad industrial efectúa una diferenciación de los campos de actividad, de las instituciones, de las funciones y de los roles, y eso de manera cada vez más fina a medida que la modernidad se profundiza.

Este modelo cultural del progreso y la razón hizo crisis y sufrió transformaciones por factores de diverso orden, tanto a nivel estructural como a nivel cultural. Los autores del MAG describen las transformaciones en cuestión a través de seis grandes ejes:

b.1) Las trayectorias sociales se desajustan. La modernidad había generado una tipología del espacio de posiciones sociales en función de clases y fracciones de clases. Aunque esta imagen sigue vigente, se ha ido haciendo 
cada vez más borrosa. Las fronteras entre las clases y los grupos sociales son más imprecisas, las trayectorias individuales menos rectas y más sinuosas, de suerte que la reproducción social transgeneracional deviene incierta.

b.2) Las desigualdades sociales se extienden y se profundizan. La masificación y el alargamiento de la educación no han implicado mayor igualdad; tampoco el aumento del promedio de las condiciones de vida. A las desigualdades clásicas, que estaban ligadas a la clase social y a cuestiones materiales, se vienen a agregar nuevas desigualdades: tensiones relacionales y familiares, endeudamiento, aislamiento social, desigualdades en el acceso a la información, etc. No solo se trata de diferencias materiales, sino también identitarias, de manera que la esfera de lo íntimo se pone mucho más en juego. En este contexto, la igualdad y la desigualdad se definen en función de "Ios recursos de los que dispone cada uno para construir su vida, para afirmar su identidad y ser reconocido por los otros" (Van Campenhoudt et al. 2005, p. 23).

b.3) Las metamorfosis de la cuestión social. Siguiendo las indicaciones de Castel (1995), los autores del MAG sostienen que, a las cuestiones y conflictos de orden colectivo, ligados a la explotación y la desigualdad en la distribución de riquezas, se agrega la cuestión de la exclusión vivida individualmente. Más allá de la inserción en el trabajo o el sistema productivo, los criterios y exigencias de participación en el intercambio social se han complejizado. La autonomía y en particular el imperativo de autonomía - a la que los individuos aspiran o través de la cual realizan sus proyectos y vidas - es un terreno que hace emerger nuevos modos de integración y exclusión social.

b.4) La des-totalización de las identidades y la heterogeneidad de las experiencias. La transmisión y la reproducción cultural es cada vez menos sólida en la medida en que existen cada vez menos universos culturales cerrados, bien delimitados, en los cuales la evolución de los individuos a lo largo de la vida seguiría un proceso relativamente estable. Como corolario de esto, no se puede reducir fácilmente el comportamiento de los individuos a categorías tales como clase, posición social, sistema, etc. Desde distintas corrientes se describe al individuo mismo como "la unidad de reproducción de la esfera social" (Van Campenhoudt et al. 2005, p. 24). El mismo individuo resulta ser también la unidad donde se encarna el "malestar" (Ehrenberg 2010) o el sufrimiento narcisista (Lipovetski 1983, Lasch 1999), la incertidumbre identitaria asociada a un Yo más fluido que substancial (Gergen 1997), o el lugar donde se precipita el "cansancio de ser uno mismo" (Ehrenberg 2000). En este nuevo orden de cosas, el individuo es empujado crecientemente a inventarse y reinventarse, sin poder contar con una "jerarquía de lógicas de acción" (Dubet 1994). Las trayectorias y experiencias sociales son cada vez más diversas, inesperadas, atípicas y heterogéneas, de suerte que no es tan obvio aprehender las experiencias de los actores a través de las categorías clásicas o los métodos habituales. Los individuos elaboran respuestas o estrategias que ya no son dadas por un marco normativo estable y obligante.

b.5) La afirmación de un sujeto reflexivo. La ruptura del marco cultural homogéneo y la heterogeneidad de lógicas de acción implican que el individuo pierde un cumulo importante de referencias con las que podía contar y ha de producir una actividad muy significativa para construir su identidad personal. A partir del momento en que se rompen las evidencias culturales, emerge una pluralidad creciente de referencias que compiten entre ellas. Disminuye la eficacia de las representaciones sociales y disminuye su poder normativo. Se abre entonces una brecha, un espacio reflexivo para el sujeto, donde podrá ejercer elecciones éticas y/o instrumentales diversas. El sujeto toma distancia del mundo de la vida, de las evidencias y de las convenciones. Se desarrolla 
así una relación al mundo más descentrada, reflexiva y procedural. Emerge una identidad "post-convencional" (Habermas 1987), donde el sujeto no se pliega a la norma, sino que es capaz de cuestionarla y de interrogar su legitimidad.

b.6) La demanda de reconocimiento, en la dirección de Honneth (2002) y otros investigadores que ponen el acento sobre la centralidad del deseo y la demanda creciente de reconocimiento (Todorov 1995, Le Breton 2002), como factor eje de la vida social contemporánea y de la experiencia individual. Dada la "des-categorización" de las identidades, el sujeto no puede referir sus logros o éxitos a su pertenencia grupal. La estima o el respeto no están garantizados por la pertenencia a tal categoría social o laboral. El individuo debe crecientemente referirse a sí mismo, operando una evaluación de sus propias prestaciones y capacidades. El reconocimiento tiende entonces a ser una realidad álgida de las relaciones, asimétricas y desiguales, entre sujetos singulares e inscritos, sobre todo, en su historia individual. De tal suerte, la exclusión, la injusticia o el fracaso son crecientemente vividos como experiencias de degradación individual y pérdida de la estima de uno mismo, y no como condiciones colectivas resultantes de conflictos también colectivos. En un cierto sentido, la centralidad de la demanda de reconocimiento psicologiza la existencia, tornando invisible parcialmente la naturaleza social de la experiencia.

\section{c) Intento de articulación de lo que está disociado}

El tercer aspecto del fundamento del MAG es que se trata de un método que, en el marco de esta segunda modernidad o posmodernidad o hipermodernidad, intenta articular desde nuevas bases lo que está disociado o fragmentado. Es decir que, frente a las transformaciones contemporáneas, no sería interesante rendir pleitesía al orden posmoderno que se fascina con una complejidad que desalienta toda ambición explicativa. Tampoco sería interesante deslizarse hacia una sociología que renunciaría a explicar lo social por lo social. Si bien es cierto que "las mutaciones en cuestión hacen más dificultosa la comprensión de las relaciones sociales y de la experiencia subjetiva de los individuos, y sobre todo de su imbricación" (Van Campenhoudt et al. 2005, p. 34), dicha comprensión no es imposible, pero se requiere renovar los métodos. Durante mucho tiempo, las teorías sociológicas pudieron dar cuenta de lo social y de la experiencia individual hasta en la esfera de lo íntimo. Hoy esa correspondencia está aparentemente rota. Algunos estiman esto deplorable y viven con nostalgia el tiempo de las ciencias sociales fuertes y coherentes. Otros se regocijan ante la caída de las disciplinas y las evidencias científicas que romperían las cadenas del academicismo. EL MAG se sostiene en una tercera vía, intentando "articular sobre nuevas bases (reflexividad, experiencia, comunicación...) lo que está disociado" (Van Campenhoudt et al. 2005, p. 34). 
d) Demarcación epistemológica de la posición de saber y postulado del sujeto reflexivo

En el fundamento del método encontramos, entonces, una postura epistemológica. EI MAG intenta hacerse cargo de las implicaciones metodológicas de lo que, en las sociedades de la segunda modernidad, ciertos sociólogos han descrito como una difusión de una relación crítica y reflexiva de los individuos con su entorno y con su experiencia. Los individuos no son idiotas culturales, sino que poseen recursos críticos, aunque en grados diversos y desiguales. EI MAG, entonces, se desmarca de la disociación clásica entre actores que viven y actúan e investigadores o pensadores que analizan. El actor posee un saber; no solo es el agente de experiencia o de encarnación de la cultura o de las representaciones sociales. El individuo puede decir algo, y en ese discurso se teje un saber reflexivo que es posible e interesante hacer emerger, y esa sería la función de un método.

Desde este punto de vista, el MAG comparte parcialmente una perspectiva epistemológica cara al psicoanálisis: el sujeto sabe mucho más de lo que la ciencia está dispuesta a reconocer, y esto se hace obvio si se escucha a ese objeto que habla, que en verdad es un sujeto (el parlêtre de Lacan). Mirado desde otro vértice, el MAG comparte la perspectiva emergente de la producción de conocimientos propia a la grounded theory (Strauss y Corbin 1994, Glaser y Strauss 2012, Pace 2016). Esta perspectiva también investiga desde abajo, dando a los individuos un lugar no solo de informantes sino de poseedores de un saber sobre los fenómenos sociales y humanos; sin duda alguna, sobre los conflictos. Sin embargo, la grounded theory opera una cierta disociación en cuanto que los niveles de análisis más complejos (axial y relacional) son operados por los investigadores y eventualmente se discuten dichos análisis con los actores (triangulación). EI MAG va más lejos: los miembros del grupo están asociados a todas las etapas del proceso, incluidos los análisis de mayor complejidad, que suben su nivel de abstracción o de generalización.

e) La organización procesual del debate y del espacio discursivo

Inspirándose en la "ética comunicativa" (Habermas 1987) y en las reglas que regulan la comunicación científica de un grupo de pares, el MAG intenta dar la forma de un debate organizado al análisis en grupo. Se intenta garantizar la libertad de cada uno, lo que supone que el intercambio no es completamente espontaneo. Se organizan las rondas donde cada uno toma la palabra en un cierto orden, respetando un protocolo para evitar las tomas de poder en el diálogo. El animador intenta ser garante de esta ética, aplicándosela, en primer lugar, a él mismo, y limitando a los participantes que se salen de esta lógica dialógica.

Así, se respeta el principio del carácter público de la discusión, al punto de que incluso las hipótesis de los investigadores o el informe del análisis son confrontados con las reacciones críticas del grupo. Se vela por preservar la libertad y la igualdad moral de los participantes en el debate. El MAG también valora y cataliza el principio de la argumentación, elaborando conocimiento progresivamente y frenando los argumentos de autoridad. Por otro lado, el MAG se refiere al principio de consenso de un modo particular: no se trata tanto de ponerse de acuerdo sobre una interpretación única, sino de ponerse de acuerdo respecto a los desacuerdos, lo que se acerca bastante de la mediación, no centrada en los resultados ni en el eventual acuerdo. ¿Cuál es la mejor manera de expresar los desacuerdos que se hacen valer en la discusión? Esa es una pregunta clave en el proceso de análisis en grupo, y probablemente también en una mediación.

Sin embargo, los autores del MAG son conscientes el carácter idealizado y un tanto etéreo de este sujeto reflexivo, descentrado y posconvencional que propone Habermas. Las personas concretas no se libran de un intercambio distante de argumentos racionales. Al contrario: la viveza que imprime el relato moviliza las pasiones, las convicciones de cada uno inundan las interpretaciones, y ahí se ponen en juego los intereses, los deseos y hasta la identidad de los actores. El ruido y la 
furia de las vidas está muy presente en el proceso. El hecho de insistir en tomar en cuenta la capacidad reflexiva y crítica del sujeto es la otra cara de la consideración de la implicación práctica y existencial de los actores sociales. Siempre hay una tensión en juego: que se instalen normas procesales no elimina las eventuales normas substanciales que atraviesan a cada individuo, el que se vele metódicamente por garantizar la igualdad moral de los participantes no elimina las desigualdades sociales entre los miembros. Es en estas tensiones y en estas "disimetrías de las relaciones sociales que el análisis en grupo encuentra su dinámica" (Van Campenhoudt et al. 2005, p. 45).

\section{El método de Análisis en Grupo (MAG) como instrumento de formación}

Nos referiremos ahora al MAG que nosotros utilizamos como instrumento de formación. Si bien en su inicio se trata de un método de investigación-acción, concebido y desarrollado en un Centro de Estudios Sociológicos, en su desarrollo posterior se ha podido observar su pertinencia en otros campos, en lo que nos interesa aquí, la mediación.

\section{a) El principio orientador del método}

Se trata de reunir durante un día a entre 15 y 20 participantes, para discutir, de una manera ordenada, una problemática que les concierne. De este modo es posible reunir en torno a una mesa a policías, jueces, trabajadores sociales y psiquiatras expertos para discutir, por ejemplo, sobre el seguimiento de los condenados en libertad condicional. El método busca permitir comprender mejor la puesta en práctica del dispositivo de libertad condicional, las diferencias entre los objetivos oficiales y su traducción por parte de los actores, las interrelaciones entre los diferentes partners implicados, los conflictos de poder o las dificultades de comunicación entre los mismos actores. Desde este punto de vista, el método es particularmente pertinente para estudiar mundos de funcionamiento en red.

El enfoque supone que el análisis sea llevado a cabo por el grupo de personas presentes, con la ayuda de investigadores que animan y controlan el proceso. No se trata entonces de un focus group ni de una entrevista grupal en los cuales los participantes son cuestionados por los investigadores; se trata de un modo participativo de construcción del saber, donde los miembros del grupo y los investigadores desarrollan juntos un trabajo reflexivo, a partir de la narración de una experiencia vivida por un miembro del grupo.

La construcción del saber común sobre el caso se realiza a partir del saber de las partes. Son los participantes quienes, a partir de su propio conocimiento, aportan datos, reaccionan a las interpretaciones de otros participantes, profundizan su conocimiento y se cuestionan a partir del saber y las preguntas de otros participantes. Los participantes son los analistas.

Si un investigador o académico, distinto al investigador que anima, está presente, participa como los otros, a partir de su propia experiencia y de su saber propio. Nos enfrentamos entonces a la construcción de un "saber hibrido" (Latour).

El investigador que anima está ahí para guiar el proceso de parto. No está ahí en posición de experto que sabe o que cosecha un saber para su propio provecho. Su rol es de ser el guardián del proceso y de las etapas del análisis. Juega un rol de facilitador, interviniendo a veces para clarificar una intervención o reformularla para sostener la inter-comprensión entre los participantes.

\section{b) El proceso de trabajo}

El proceso de trabajo tal como lo utilizamos en la formación antes descrita reposa sobre tres grandes etapas: 


\section{b. 1) Primera etapa: el relato}

Uno o varios participantes son invitados a presentar un relato breve de una historia vivida. El grupo elige colectivamente uno de los relatos presentados. El relato elegido es entonces contado con detalles. El narrador termina presentando lo que, según él, está en juego en ese relato ("lo que me parece importante en este relato es esto o aquello", etc.) .

El relato tiene varias ventajas importantes: anclará el trabajo del grupo en la experiencia concreta de los participantes, lo que generalmente aumentará el interés y la implicación en el proceso. Esto es particularmente útil para los participantes poco familiarizados con el trabajo intelectual o científico y que pueden desconfiar de discursos muy generales, o abrigar reticencias ante lo que a veces perciben como ideas preconcebidas de los investigadores. El relato, al implicar a los actores, disminuye también la distancia o la actitud defensiva frente a los investigadores.

Desde un punto de vista más estrictamente epistemológico y metodológico, el relato tiene una ventaja crucial respecto a las ideas u opiniones que los actores podrían también expresar: el relato funciona para el grupo como una suerte de "principio de realidad" al cual los actores van a referirse en el proceso del análisis (Van Campenhoudt et al. 2005). Esto quiere decir que la referencia al relato hará más difícil que los participantes movilicen ideas generales, que no estén conectadas de manera pertinente a esta realidad. Para que este efecto regulador ocurra, es clave que los relatos sean propuestos y elegidos por los actores mismos y no impuestos por los intereses de los investigadores o facilitadores. Es gracias al relato que en el MAG no se discuten ideas en el aire, sino que se analiza en conjunto una situación precisa que es reveladora de cuestiones complejas. El relato deviene un material empírico común para todos los miembros del grupo, dando lugar a una discusión fecunda en la medida en que todos pueden referirse a la misma experiencia concreta.

La historia relatada permite aprehender a la vez la experiencia individual y las interacciones sociales, articula al mismo tiempo el contexto concreto de la acción y la realidad simbólica del narrador. Así, se aglutinan diversos órdenes que confieren al relato todo su interés para las ciencias sociales y para la mediación, campos donde, vale la pena recordarlo, intentamos comprender no la experiencia de los actores, sino el relato y la narración que hacen de ella.

Se entiende entonces que el MAG vele porque los relatos sean propicios al trabajo del grupo y, para ello, el investigador precisará algunas características de un buen relato: que esté conectado con el objetivo que reúne al grupo, que sea real y que el narrador haya vivido esa experiencia contada. Lo primero, entonces, es que debe referirse a eventos o experiencias que tengan un interés para el objetivo del grupo (pregunta de investigación, problema o conflicto a resolver, etc.). La segunda condición es que el relato debe ser una historia real, con un desarrollo en el tiempo, largo o corto. No se trata de contar un evento puntual, del estilo "el marido golpeó a su mujer", o "la dirección de la empresa llamó a la policía", sino de situar el evento en una trama y en una textura temporal. Pero la historia no puede ser ficticia o arreglada arbitrariamente para que se preste al análisis; el relato debe ser contado con objetividad y veracidad, puesto que esto tiene un efecto en las emociones del narrador y de los que escuchan y, por lo tanto, en la implicación subjetiva que el relato podrá movilizar.

\section{b.2) Segunda etapa: las interpretaciones}

Esta segunda etapa constituye el punto de partida del proceso de producción colectiva y democrática de análisis de un caso. Se realiza una primera vuelta de interpretaciones: se le pide a cada participante que proponga dos o tres interpretaciones del relato, a partir de su propia experiencia (por ejemplo: "me sorprende el hecho de que el director de la escuela haya estado presente en la entrevista"; "encuentro interesante que el mediador haya decidido interrumpir el 
proceso de discusión y dar tiempo al tiempo", etc.). La primera vuelta termina con la reacción del narrador a las diferentes interpretaciones propuestas por el grupo.

Posteriormente se organiza una segunda vuelta de interpretaciones, en el mismo orden que la primera. Las mismas directivas son dadas, con una diferencia: se alienta a los participantes para que reaccionen a las interpretaciones dadas por los otros en la primera vuelta. Se termina, una vez más, con las reacciones del narrador. Esta consigna alienta a escuchar a los otros participantes, cuyos puntos de vista divergen del propio. El confrontarse a una diversidad de interpretaciones de un mismo relato conduce frecuentemente a cada participante a una toma de distancia reflexiva respecto de su propia visión de las cosas y respecto a sus propias reacciones ante los eventos. Esto es posible a condición de que los argumentos de autoridad, las relaciones de poder y desigualdad, sean abolidos, al menos durante el tiempo en que el grupo trabaja. Por lo tanto, es sobre todo en esta fase donde el investigador o facilitador debe velar por garantizar la igualdad moral de los participantes en el intercambio. Su acción será crucial en cuanto a mantener las condiciones de la ética comunicativa a las que nos referíamos antes, favoreciendo un debate igualitario y libre.

La experiencia muestra que esta fase es muy apreciada por los participantes, pues se produce colectivamente un material importante y a veces muy abundante, permitiendo a cada uno de hacer la experiencia de cómo sus interpretaciones son escuchadas y consideradas en el análisis que se elaborará progresivamente.

\section{b.3) Tercera etapa: el análisis}

Con la ayuda del o de los investigadores, el grupo intenta reunir las interpretaciones hechas durante la segunda etapa en torno a grandes temas articuladores (por ejemplo: "la postura del mediador", "la temporalidad de la mediación", "Ios límites de la mediación"). Este momento de trabajo colectivo tiene dos particularidades: primera, en esta etapa se trabaja sólo sobre el material recogido hasta ahí, no se introducen nuevas interpretaciones. Segunda: en el interior de cada tema, se reúnen las interpretaciones, tipificándolas como "convergencias" y "divergencias". Una interpretación es convergente si ha sido propuesta por varios participantes o si no ha sido contradicha; dos interpretaciones son divergentes si son contradictorias, conflictivas o incompatibles (por ejemplo: "el mediador se salió de su rol" contra "su intervención ayudó a clarificar el conflicto para las partes").

A partir de la puesta en evidencia de estos grandes temas, emerge un esquema de síntesis y que tiene tres características:

- Aparece como un intento de, a través del proceso de discusión colectiva, reformular el problema inicial;

- La reformulación pone en valor la expresión de los conflictos de interpretaciones sobre la situación. Al hacer esto, el proceso de análisis hace aparecer como normales los conflictos de puntos de vista, en la medida en que estos se integran en una problematización más general. En el seno de esta problematización o una teoría emergente sobre asuntos globales, las posiciones cobran sentido incluso cuando son contradictorias;

- La reformulación tiene como efecto permitir una mejor comprensión del punto de vista del otro. A veces, moviliza una toma de distancia de un participante respecto a su punto de vista inicial.

Esta síntesis general de las características del esquema de análisis puede parecer un poco abstracta. Es el límite de esta comunicación, donde debemos aceptar el hecho que la manera más eficaz de apreciar las virtudes (y defectos) de un método es hacer la experiencia de usarlo. 


\section{Conclusiones: las relaciones entre el MAG y la mediación}

Es probable que la lectura del proceso seguido por el método deje entrever, al lector familiarizado con la mediación, diversos puntos de conexión. A continuación quisiéramos explicitar lo que, según nuestra experiencia en la formación, nos parecen ser los puntos comunes fundamentales entre el MAG y la mediación:

a) Al igual que la mediación, el MAG toma la forma de un debate procesual, realizado por etapas. Este debate participa de una lógica que busca favorecer la expresión de una "ética de la comunicación" (Habermas 1987). El MAG se sitúa en el polo puesto de un saber experto. La construcción del saber es inductiva y parte de abajo, desde la experiencia de los actores, de sus narraciones e interpretaciones. Por lo tanto, el proceso hace existir el postulado según el cual el saber respecto a la situación problemática pertenece a las partes y no a los investigadores o los expertos. Las partes son consideradas como sujetos y no como objetos del proceso. Como lo indicamos antes, las partes son sujetos reflexivos, considerados capaces de reflexionar por ellos mismos respecto a la situación problema que les concierne.

Nos parece claro que la lógica de la discusión, guiada por etapas, acompañada por el animador del MAG o el mediador en su dispositivo, garantiza una igualdad moral entre los participantes en el proceso de discusión. Si bien el discurso es libre, es también regulado, sobre todo para evitar la toma de poder de unos o de otros. ${ }^{2}$

La tercera parte presente, investigador o académico, renuncia a la posición de superioridad. Se pone en posición baja, del mismo modo que un mediador que no sabe lo que es mejor para las partes, solo sabe escuchar y a veces ayudar a que las partes se escuchen entre ellas. Debe ser capaz de escuchar, de mirar, de dosificar sus intervenciones, a veces de llamar a un participante al orden si se extravía... No puede permitirse ningún juicio moral sobre el fondo de lo que se trata en la discusión.

Es el método lo que va funcionando como factor de legitimidad de la discusión, y esta se inscribe en un proceso en el que cada etapa está constituida sobre la base de lo aprendido en la etapa previa. Se avanza paso a paso y el facilitador empuja al grupo a usar lo que se ha ido produciendo en las etapas previas.

b) Como la mediación, el MAG trabaja sobre realidades vividas y no sobre categorías abstractas. Se parte de la narración de una historia, contada tal como fue vivida por el narrador. Los participantes reaccionan a partir de su propia percepción y experiencia. Esto quiere decir que las interpretaciones de unos y de otros son tomadas en serio y constituyen el material a partir del cual se avanza.

Los participantes implicados en un análisis son sujetos en situación: en el proceso pondrán en juego sus convicciones, su identidad, sus intereses, sus emociones y no solo sus opiniones. El modo de implicación es muy distinto a una discusión clásica donde se intercambian solo pensamientos o ideas. El discurso toma tonalidades más complejas y arraigadas en la existencia de cada uno. Es por esto que es importante en el MAG, como en la mediación, que la expresión de conflicto de punto de vista sea valorada, aunque sea en términos civilizados.

c) Como en la mediación, el proceso de reformulación es central. Al término del MAG, el objetivo es problematizar de otro modo la situación inicial y producir un movimiento de las representaciones presentes al comienzo. La reformulación, a partir del intercambio de puntos de vista, permite cambiar la realidad percibida del problema. Pero existe un límite fundamental a la reformulación: es necesario que la nueva versión, co-construida entre varios, siga siendo legítima a los ojos de las partes. No puede, entonces, construirse distanciándose de las partes; debe

\footnotetext{
2 De manera análoga, cuando Jacques Faget (2010) da cuenta del carácter "cooperativo" del proceso de mediación, indica que para ello es necesario que el intercambio esté "organizado en torno a algunas reglas que permitan el respeto mutuo. Esto supone que el mediador sepa crear un clima empático en un ambiente adaptado, que estimule la expresión de las personas y vele por el equilibrio relativo de los tiempos en que cada uno habla" (Faget 2010, p. 102)
} 
permanecer anclada en sus relatos y debe contar con su aprobación. Este anclaje es central, pues genera la experiencia de que la elaboración progresiva que se hace en grupo no es una pura construcción; sigue existiendo una referencia, dada por esa suerte de principio de realidad que instala el relato. Esto da valor a lo que el grupo elabora y pone a distancia el cinismo desencantado que acompaña frecuentemente la deriva constructivista, tan cara a un cierto posmodernismo.

d) Como en la mediación, el rol del animador es el de ser un partero, ayudar a que el grupo haga emerger lo que sabe, aunque a veces esta conciencia no está presente en el comienzo del proceso. Para esto, el animador, como el mediador en su proceso, debe velar por ciertas cosas básicas: debe hacer respetar las reglas de la discusión, ayuda a la co-construcción progresiva del relato y permanece neutro, esto es, puede mostrar empatía, reinyectar equidad en el proceso de discusión, pero no puede tomar partido y no debe mostrar sus preferencias. Nos parece que hay algo del mismo orden en la mediación, que confía en las capacidades de los actores para encontrar lo que es bueno, pertinente o eficaz para ellos. Aunque el mediador pueda a veces sorprenderse, hace un esfuerzo por captar la lógica en juego en los modos errantes, inesperados o no convencionales de tratar el conflicto

e) Finalmente, en ciertos casos, el MAG tiene un objetivo o un efecto de mediación. Permite que el conflicto se despliegue, permite entrar en el punto de vista del otro y desbloquear los antagonismos. Al menos el ponerse de acuerdo respecto a los desacuerdos da una perspectiva diferente, pues, aunque el conflicto persista, emerge eventualmente la conciencia de que algo se puede hacer con el otro. Se opera algo así como una restitución de la alteridad, probablemente catalizada por la ética de la discusión, el método y el proceso, y no necesariamente por los atributos morales de los individuos.

El carácter vívido del relato, carácter que no tienen las ideas generales o las opiniones abstractas, merece una reflexión final. Un relato está más o menos lleno de alusiones, de metáforas, de subentendidos, o incluso de misterio y de secreto, cuando toma la forma de una historia casi novelesca o de una intriga. Estos rasgos movilizan en los actores un deseo de ver, pues el relato da una imagen, una representación casi plástica de las cosas. Es así como el relato suscita a veces una experiencia sensual y sensorial, más que intelectual. Sin embargo, el relato está hecho de fonemas y de palabras, su realidad es lingüística y no ofrece ninguna imagen directamente. Para ver, el actor tendrá que escuchar y representarse algo. De este modo, el receptor liga sus propias representaciones al discurso, de tal suerte que podríamos decir que el receptor ve algo en él, y no tanto en el relato. Es su propia subjetividad la que es vista. Al escuchar un relato, es una suerte de visión de segundo grado lo que se precipita, de tal suerte que no sería inexacto decir que, a veces, es el relato el que capta al sujeto y no al revés. Es lo que ocurre cuando un actor de un MAG o una mediación enrojece a la escucha de un relato, como si alguien lo mirara en ese instante preciso o alguien adivinara lo que siente íntimamente. El relato toca la intimidad y la subjetividad de manera mucho más rica, sutil e intensa que el pensamiento.

Desde un punto de vista de la psicología clínica y del psicoanálisis, es dable pensar que el relato, en cualquier dispositivo dialógico, instaura un juego entre lo visible y lo invisible, de tal suerte que el sujeto implicado demanda al relato: “imuéstrame algo!", y el relato responde: “imírate!" (García 1999); es como si el relato nos situara ante una demanda que nos hace otro, ante un deseo que una alteridad tiene respecto de nosotros. Es por esto por lo que el sujeto no puede escapar a sí mismo y por lo que el relato lo empuja a la implicación personal. Es algo de este orden lo que quiere decir que un relato no solo nos informa de algo, sino que nos transmite algo.

Si el objeto que nos propone el relato es un objeto deseante, el sujeto se verá obligado a realizar un trabajo psíquico y no podrá tomar un posición pasiva de mero espectador o auditor. Como nos enseña el psicoanálisis, son los objetos donde hay una alteridad deseante los que imponen un trabajo a la vida psíquica. El objeto 
objetivado, el objeto inerte o abstracto no son sino explicaciones o informaciones que no tocan el deseo.

El ejercicio que hemos propuesto tiene sus límites, lo indicamos desde un inicio. Los parentescos entre el MAG y la mediación no implican que la mediación deba casarse con este modelo, pues es relevante para sus posibilidades de acción el conservar el hibridismo de los modelos y tal vez de los métodos. Con todo, cada mediador ganaría en coherencia y fecundidad de su práctica si hace el esfuerzo por dar cuenta de los caminos que transita, las vías que sigue repetidamente en su trabajo, por parafrasear de nuevo a Lalande (1997). Pensamos que el método de análisis en grupo puede contribuir a dar forma al modo en que los dispositivos de la mediación movilizan o no ciertos procesos. Dar forma no es escudarse en un puro formalismo, sino que implica también aceptar lo que de artesanía hay en toda implicación con un terreno, en las vidas y en el conflicto.

\section{Referencias}

Castel, R., 1995. Les métamorphoses de la question sociale: Une chronique du salariat. París: Fayard.

Dubet, F., 1994. Sociologie de l'expérience. París: Seuil.

Ehrenberg, A., 2000. La fatigue d'être soi: Dépression et société. París: Odile Jacob.

Ehrenberg, A., 2010. La société du malaise. Paris: Odile J acob.

Faget, J., 2010. Médiations: les ateliers silencieux de la démocratie. Toulouse: Erès.

García, M., 1999. L'altérité, le regard et la réciprocité. Les représentations culturelles de la souffrance dans la culture populaire chilienne: approche anthropo-psychanalytique. Tesis de Doctorado en Psicología. Université Catholique de Louvain, Bélgica.

Gergen, K., 1997. El Yo saturado: Dilemas de identidad en el mundo contemporáneo. Buenos Aires: Paidós.

Glaser, B.G., y Strauss, A., 2012. La découverte de la théorie ancrée: Stratégies pour la recherche qualitative. París: Armand Colin.

Habermas, J., 1987. Théorie de l'agir communicationnel. París: Fayard.

Honneth, A., 2002. La lutte pour la reconnaissance. París: Cerf.

Lalande, A., 1997. Vocabulaire technique et critique de la philosophie. París: PUF.

Lasch, C., 1999. La cultura del narcisismo. Santiago de Chile: Andrés Bello.

Le Breton, D., 2002. Conduites à risque: des jeux de mort au jeu de vivre. París: PUF, col. Quadrige.

Lipovetsky, G., 1983. L'ère du vide: Essais sur l'individualisme contemporain. París: Gallimard.

Maturana, H., 1989. El árbol del conocimiento: las bases biológicas del entendimiento humano. Santiago de Chile: Universitaria.

Pace, S., 2016. Contested concepts: negotiating debates about qualitative research methods such as Grounded Theory and Autoethnography. En: B. Harreveld et al., eds., Constructing Methodology for Qualitative Research: Researching Education and Social Practices. Londres: Palgrave Macmillan, pp. 187-200.

Ricoeur, P., 1965. De l'interprétation: essai sur Freud. París: Seuil.

Ricoeur, P., 1983. Temps et Récit. París: Seuil.

Schwartz, O., 1993. L'empirisme irreductible [postfacio]. En: N. Anderson, Le Hobo: Sociologie du sans-abri. París: Nathan. 
Strauss, A., y Corbin, J., 1994. Grounded Theory Methodology: An Overview. En: N. Denzin y Y. Lincoln, eds., Handbook of Qualitative Research. Thousand Oaks, CA: Sage, pp. 273-285.

Todorov, T., 1995. La vie commune: Essai d’anthropologie générale. París: Seuil.

Van Campenhoudt, L., Chaumont, J.M., y Franssen, A., 2005. La méthode d'analyse en groupe. París: Dunod.

Van Campenhoudt, L., Franssen, A., y Cantelli, F., 2009. La méthode d'analyse en groupe. Sociologies [en línea], Théories et recherches. Disponible en: http://sociologies. revues.org/2968 [Con acceso el 11 de mayo de 2018]. 